\title{
COMPARATIVE ANATOMY OF THE VENTRAL REGION OF ANT LARVAE, AND ITS RELATION TO FEEDING BEHAVIOR. ${ }^{1}$
}

\author{
By Ronald S. Petralia ${ }^{2}$ and S. B. Vinson \\ Department of Entomology \\ Texas A\&M University \\ College Station, Texas 77843
}

\section{INTRODUCTION}

The morphology and systematics of the larvae of ants have been studied in great detail by George C. and Jeanette Wheeler in many articles and is summarized in Wheeler and Wheeler (1976). From the studies of many authors, especially the former and William M. Wheeler $(1918,1920)$, it is apparent that the mature larvae of many species of ants are fed solid food by the adult worker ants, which place the food on the ventral region of the larvae. Although the Wheelers describe the general morphology of ant larvae, they have not studied the ventral feeding region as a distinct unit, except in larvae where this region is the most specialized (e.g. Pseudomyrmecinae and Camponotini). Consequently, we intend in this study to examine the fine detail of the ventral region of larvae in the hope of clarifying homologies in morphological adaptations for feeding on solid food.

\section{Materials AND Methods}

Mature larvae of 15 species of ants from 6 subfamilies were examined, including:

Dorylinae

Neivamyrmex nigrescens (Cresson). Collected in Portal (Cochise

Co.), AZ (July, 1977), and identified by J. Mirenda. Three specimens examined with the scanning electron microscope )SEM).

\footnotetext{
${ }^{1}$ Approved as TA 15824 by the Director of the Texas Agricultural Experiment Station in cooperation with ARS, USDA. Supported by the Texas Department of Agriculture interagency agreement IAC-0487 (78-79).

${ }^{2}$ Current address: Department of Biology, St. Ambrose College. 513 West Locust Street, Davenport, Iowa 52803.

Manuscript received by the editor May 20, 1980.
} 
Ponerinae

Leptogenys elongata (Buckley). Collected from Sonora Research Station (Edwards Co.), TX (July 9-11, 1973), and identified by A. C. F. Hung. Three specimens examined with SEM.

Pachycondyla villosa (Fabricius). Collected from Alamo (Hidalgo Co.), TX, at Santa Ana National Wildlife Refuge (Aug. 15-17, 1973) and identified by A. C. F. Hung. Three specimens examined with SEM.

Odontomachus clarus Roger. Collected from Uvalde (Uvalde Co.), Tx (Aug. 8, 1973), and identified by A. C. F. Hung. Two specimens examined with SEM.

Pseudomyrmecinae

Pseudomyrmex pallidus F. Smith. Collected from Alamo (Hidalgo Co.), TX, at Santa Ana National Wildlife Refuge (Aug. 15-17, 1973) and identified by A. C. F. Hung. Two specimens examined with SEM.

Pseudomyrmex gracilis mexicanus Roger. Collected from Manuel, Tamaulipas, Mex. (Feb. 17, 1973), from Acacia cornigera by G. C. Gaumer. Identified by A. C. F. Hung. Five specimens examined with SEM.

Myrmicinae

Pogonomyrmex barbatus (F. Smith). Reared from newly mated queens collected from College Station (Brazos Co.). TX (July 1979) by D. and D. Ball. Identified by J. Mirenda and R. Petralia One specimen examined with SEM.

Crematogaster laeviuscula Mayr. Reared from colony collected from Port Aransas (Aransas Co.), TX (April 14, 1979), by W. Foerster. Identified by J. Mirenda and R. Petralia. Four specimens examined with SEM.

Monomorium pharaonis (Linnaeus). Reared from colony collected from College Station (Brazos Co.), TX (late winter, 1979), by D. Bogar. Identified by J. Mirenda and R. Petralia. Two specimens examined with SEM.

Solenopsis molesta (Say). Reared from colony collected from colony of $S$. invicta Buren, from Plantersville (Montgomery Co.), TX (April 12, 1979), by R. Petralia. Identified by J. Mirenda and R. Petralia. Final determination was corroborated by the presence of anterior labial spinules on the larvae (Wheeler and Wheeler, 1955). Three specimens examined with SEM. 
Trachymyrmex septentrionalis McCook. Collected from College Station (Brazos Co.), TX (May 12, 1964), by P. Adkisson. Identified by M. R. Smith. Two specimens examined with SEM. Atta texana (Buckley). Reared from 1 year old colony collected from Ratides Parish, LA (1975 queen), and identified by J. Moser. Five specimens examined with SEM.

Dolichoderinae

Iridomyrmex pruinosum Roger. Reared from Colony collected from College Station (Brazos Co.), TX (April 25, 1979) by R. Petralia. Identifed by J. Mirenda and R. Petralia. Three specimens examined with SEM.

Formicinae

Colobopsis pylartes Wheeler. Collected from Davy Crockett National Forest, TX (July 19, 1973), and identified by A. C. F. Hung. Three specimens examined with SEM.

Camponotus rasilis Wheeler. Reared from colony collected from College Station (Brazos Co.), TX (early spring, 1976), by M. R. Barlin. Identified by J. Mirenda and R. Petralia. Four specimens examined with SEM.

All species were identified from adults. Collected material from which specimens were obtained is available in the insect collection of the Department of Entomology, Texas A\&M University, College Station, Texas, 77843. Both adults and larvae and/or prepupae are available for all species except $P$. barbatus and $C$. laeviuscula (adults only).

P. barbatus, C. laeviuscula, M. pharaonis, S. molesta, and $I$. pruinosum were collected and reared according to the techniques described for Solenopsis invicta Buren (Petralia and Vinson 1978). C. rasilis was reared in a large bucket, brood being maintained in Wilson cells and petri dishes covered with a red plastic film. Atta texana was reared by Dr. John Moser (USDA Forest Service, Southern Forest Expt. Station, 2500 Shreveport Hwy., Pineville, Louisiana 71360). Larvae of $N$. nigrescens were fixed in $70 \%$ ethanol for 2 years. The remaining species were obtained from the insect collection of the Department of Entomology, Texas A\&M University, and had been fixed in $80 \%$ ethanol for up to 6 years.

Specimens from the insect collection and $N$. nigrescens were subsequently refixed in $3 \%$ glutaraldehyde- $3 \%$ formalin for 3 days or more, post-fixed in osmium tetroxide, dehydrated, critical point dried, 
mounted on metal stubs with Tube-Coat ${ }^{\mathrm{TM}}$, metal coated, and examined in a JEOL JSM-35 SEM at $20-25 \mathrm{kV}$.

Specimens of all other species were mounted on metal stubs with Tube-Coat ${ }^{\mathrm{TM}}$ and examined alive in a JEOL JSM-35 SEM at $15 \mathrm{kV}$.

Sectioning of the trophothylax of P. g. mexicana and P. pallidus was carried out after refixation, but prior to post-fixation. This was accomplished by splitting the larva longitudinally with a hand-held razor blade.

\section{RESULTS}

DORYLINAE

Neivamyrmex nigrescens - (Figs. 1, 2). There is no distinct attenuation into a neck (Fig. 1). Ventral region of body segments bear similar vestiture, which includes numerous long, simple hairs and rows of blunt spinules, both of which continue to the dorsal surface (Fig. 1). Most spinules point straight outward or slightly posterior (Fig. 2).

PONERINAE, PONERINI

Leptogenys elongata - (Figs. 3-6). Ventral body region bears only a few minute hairs, which are most numerous on the thorax (which attenuates to form the "neck" (Fig. 3)). Large cone-shaped tubercles laterally flank this region, although they become more medial after the 3rd abdominal segment (Figs. 3, 4). Each tubercle bears 6-9 long, simple hairs approximately $1 / 3$ of the distance from the base; this basal $1 / 3$ is distinctly broader than the tapering apex. The apex bears a few blunt spinules or papillae. There are numerous rows of posteriorly projecting spinules on the ventromedial surface of the thorax (Fig. 6) and a few rows on the 1st abdominal segment. A unique cuticular structure is found on the 3rd abdominal segment (Fig. 4). It is roughly ovoid, tapering posteriorly, and consists of 9-10 transverse ridges (Fig. 5) surrounded by small papillose protuberances.

Pachycondyla villosa-(Figs. 7-9). The distinct neck is formed by the thorax and 1 st abdominal segment. The ventral body region bears only a few, scattered, minute simple hairs. This region is flanked laterally by elongate, cone-shaped protuberances bearing spinules and a few hairs. These protuberances gradually approach the ventral midline as they near the anus, thus enclosing an elongate, sub-ovoidal region from the neck to the anus. Spinules in short rows are formed in a unique arrangement on the ventral region. Those on the neck form 


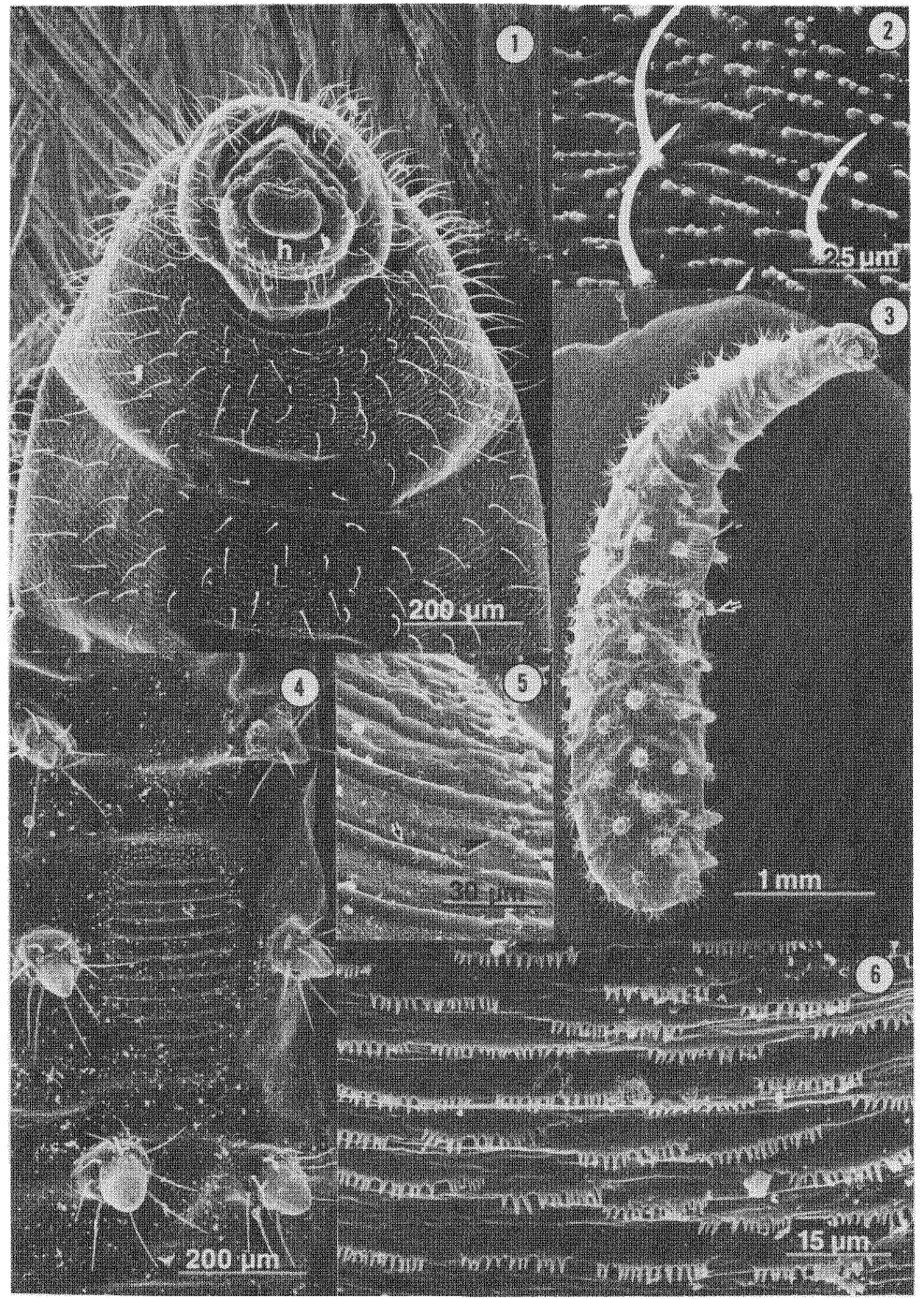

Figs. 1-6. Fig. 1. Anteroventral body region of Neivamyrmex nigrescens. Head (h). Fig. 2. High magnification, from Fig. 1 of $N$. nigrescens, of hairs and rows of spinules. Fig. 3. Leptogenys elongata showing ventral ridged structure (large arrow) on 3rd abdominal segment and tubercles (small arrow). Fig. 4. High magnification, from Fig. 3 of $L$. elongata, of ridged structure and tubercles. Fig. 5. High magnification of ridged structure of $L$. elongata showing ridges (small arrow) and papillose protuberances (large arrow). Fig. 6. Posteriorly pointing ventral mesothoracic spinules of $L$. elongata. 


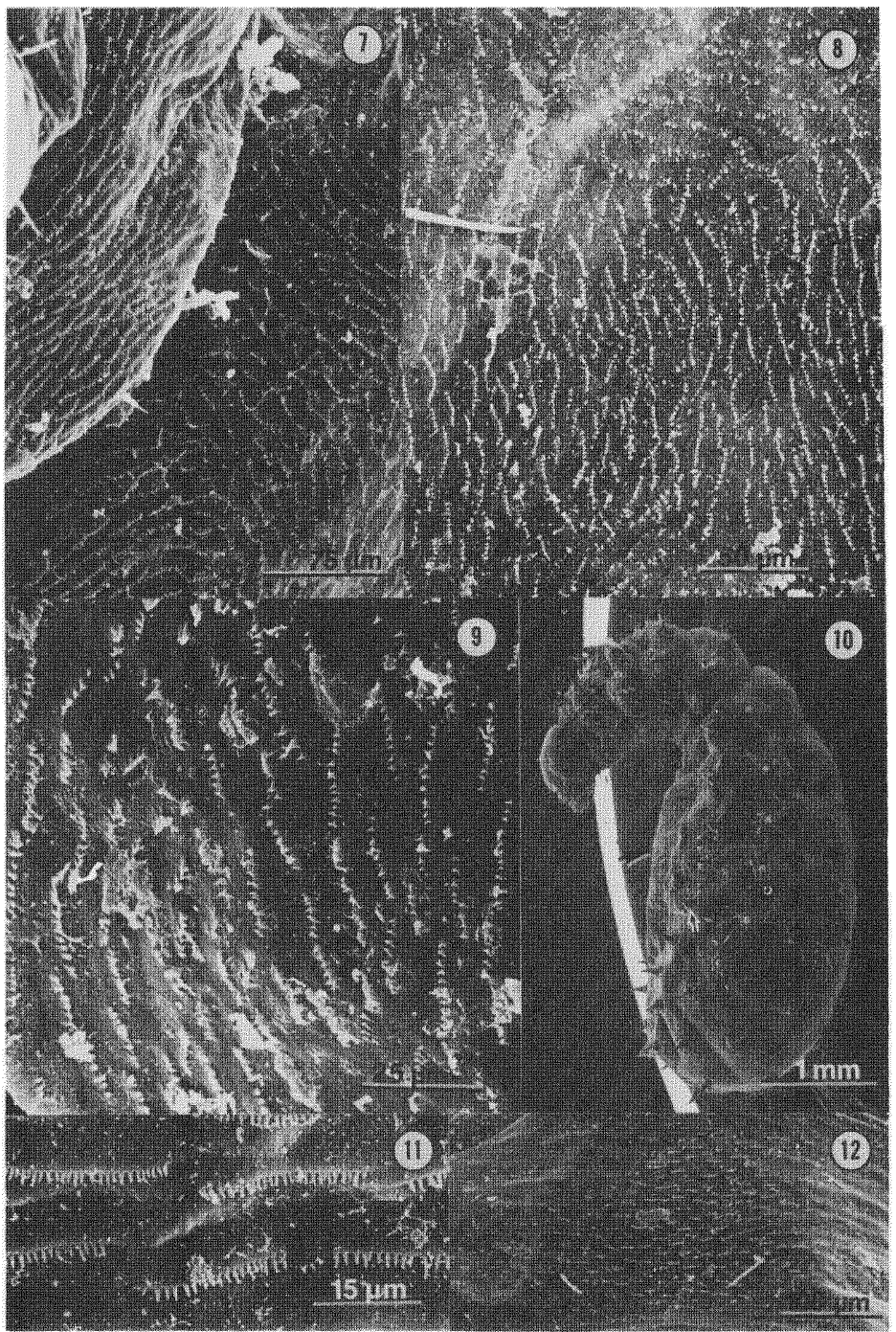

Figs. 7-12. Fig. 7. Pachycondyla villosa. Note semicircular pattern (lower right) of ventral prothoracic spinules. Portion of the left side of the head is also visible (left portion). Fig. 8. Posteroventral region of $P$. villosa showing circles of spinules of a segment. Fig. 9. High magnification of circles of spinules of posteroventral region of $P$. villosa. Fig. 10. Lateral view of Odontomachus clarus. Note posteroventral region (large arrow), and surrounding tubercles (small arrow). Fig. 11. Posteriorly pointing, ventral mesothoracic spinules of $O$. clarus. Fig. 12. Posteriorly pointing spinules of a segment of the posteroventral region of $O$. clarus. 
an almost semicircular arrangement on each segment, with anterior spinules pointing posteriorly and lateral spinules pointing medially (Fig. 7). A similar arrangement of spinules is found on the remaining abdominal segments anterior to the anus. However, on these segments the concentric circle of short rows of spinules is complete, including posterior spinules which point anteriorly (Figs. 8, 9). PONERINAE, ODONTOMACHINI

Odontomachus clarus - (Figs. 10-12). Neck attenuated as in the Ponerini (Fig. 10). Ventral body region bears only a few small, simple hairs. This region is flanked laterally by elongate cone-shaped protuberances (which continue onto the dorsal surface) bearing 4-6 long simple hairs near the apex (Fig. 10). Numerous rows of posteriorly pointing spinules occur medioventrally on at least the first 8 body segments (Figs. 11, 12). The ventral surface of the prothorax also bears a pair of fleshy tubercles anteriorly.

PSEUDOMYRMECINAE

Pseudomyrmex pallidus - (Figs. 13, 14). The structure and vestiture of the trophothylax are similar to those in $P . g$. mexicanus although in the specimen examined, the trophothylax was tear-drop shaped in longitudinal section and the segments were indistinct.

Pseudomyrmex gracilis mexicanus - (Figs. 15-17). The trophothylax is well developed. It is formed from the inverted ventral surfaces of the thorax and 1st 2 abdominal segments. The surface of the trophothylax bears numerous rows of spinules (Figs. 15, 16). Spinules on the thoracic and 1st abdominal segments point towards the posterior boundary of each segment (Fig. 15); those on the 2nd abdominal segment point towards the anterior boundary of this segment. The latter spinules cover the posterior lip of the trophothylax. The posterior portion of the 2 nd abdominal segment, as well as the succeeding segments, bears numerous, straight, simple hairs (Fig. 16). In specimens where part of the trophothylax is extruded, the spinules on the extruded region point posteriorly (Fig. 17). The lateral lips of the trophothylax bear spinules pointing medially (Fig. 17).

MYRMICINAE, MYRMICINI

Pogonomyrmex barbatus - (Figs. 18-21). The thorax is attenuated (Fig. 18). Ventral body region bears numerous medially pointed hairs, most of which are denticulate on the distal half. Numerous posteriorly pointing spinules in short rows occur on the ventral region of the thorax and 1st abdominal segment. Numerous short 


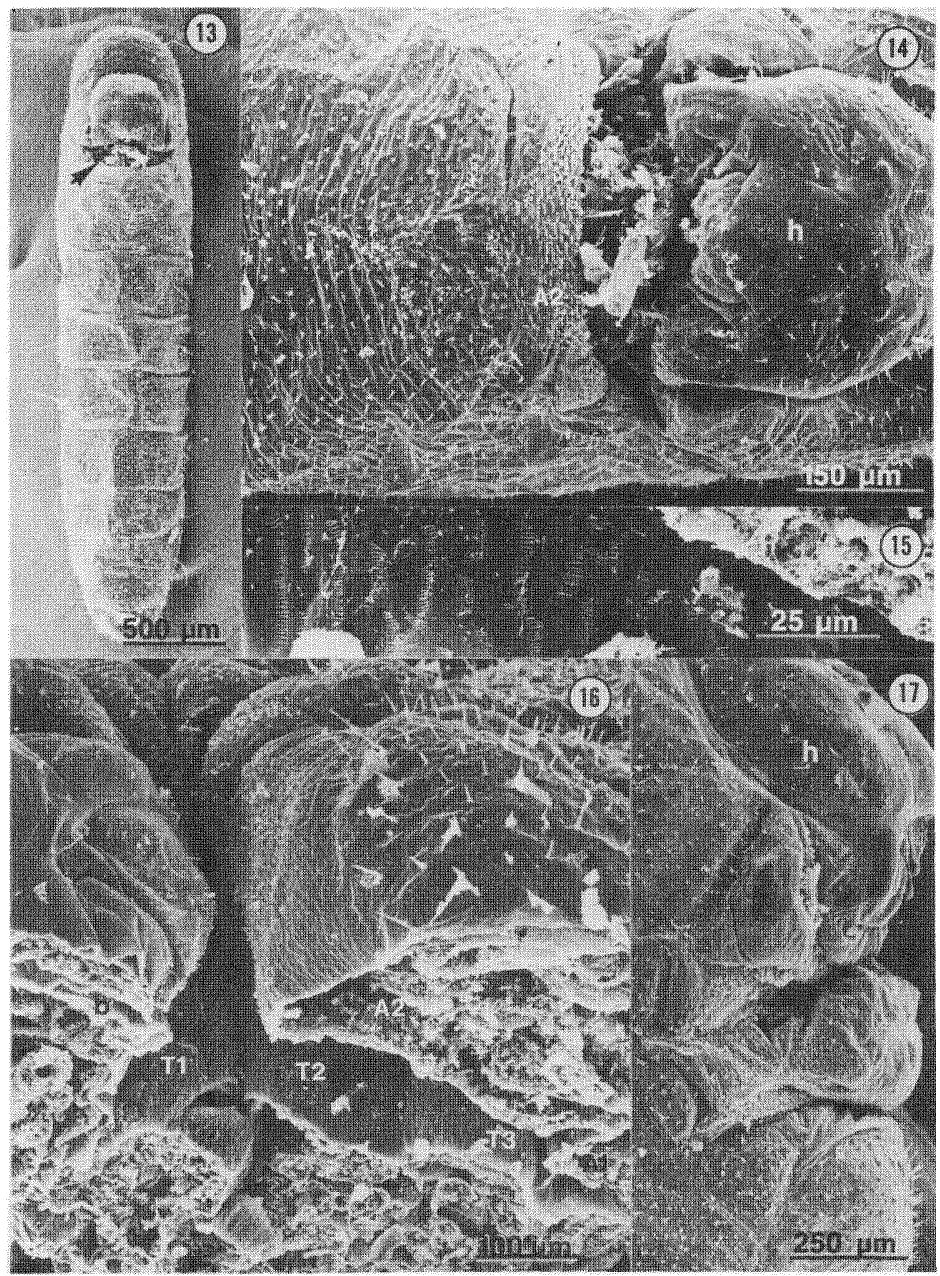

Figs. 13-17. Fig. 13. Ventral view of Pseudomyrmex pallidus showing food in trophothylax (arrow). Fig. 14. High magnification of food in trophothylax of $P$. pallidus. Note anteriorly pointing spinules on 2 nd abdominal segment (A2). Head (h). Fig. 15. Posteriorly pointing metathoracic spinules in trophothylax of Pseudomyrmex gracilis mexicanus. Fig. 16. Section through trophothylax of $P$. g. mexicanus. Note buccal cavity (b), and segments: prothorax (TI); mesothorax (T2); metathorax (T3); 1st abdominal (A1) and 2nd abdominal (A2). Fig. 17. Lateral view of extruded trophothylax of $P . g$. mexicanus. Note rows of spinules on metathorax (arrow). Head (h). 
rows of posteriorly pointing spinules are on the anteroventral region of abdominal segment 2 , while a very few (less than 10 ) anteriorly pointing spinules are on the posteroventral region of this segment (Fig. 19). Numerous short rows of posteriorly pointing anteroventral spinules and anteriorly pointing posteroventral spinules occur on each of abdominal segments 3-5 (Figs. 20, 21). Abdominal segment 6 bears only a few spinules pointing in each direction, while segment 7 bears very few spinules. Adult queen ants were observed to place solid food on the posteroventral region of larvae, which readily fed upon it. MYRMICINAE, CREMATOGASTRINI

Crematogaster laeviuscula - (Figs. 22, 23). Head closely appressed to body (Fig. 22). Anteroventral body region bears a few, small, simple hairs, those on prothorax in 2 transverse rows, those on succeeding segments in 1 transverse row (Fig. 22). No evidence of spinules except for groups of a few papillae located laterally near segmentally arranged groups of pleats (Fig. 22, 23).

MYRMICINAE, SOLENOPSIDINI

Monomorium pharaonis - (Figs. 24-26). Head close to body, thorax curved but not forming a distinct "neck" (Fig. 26). Hairs of anteroventral body region all bifid, except for those on prothorax, which bears simple, branched, or bifid hairs. Apices of hairs of ventral region of prothorax and mesothorax (and most of metathorax) straight, whereas most other body hairs with hooked apices (Fig. 25). Spinules of thoracic region mostly point posteriorly (Fig. 24), while those of 2 nd and 3 rd abdominal segments point anteriorly. First abdominal segment bears only 2-3 indistinct spinules.

Solenopsis molesta - (Figs. 27-29). Head positioned as in $M$. pharaonis (Fig. 27). Anteroventral region (1st 6 body segments) bears mostly straight, simple hairs (some with branched tips) (Fig. 28). Each segment bears a single transverse row of about 8 simple hairs. The medial bare region between the most medial pair of hairs is especially wide on the thoracic segments. Remaining body hairs are bifid with hooked tips. Hairs papillose (Fig. 29). The rows of spinules on the medial region of each thoracic segment point posteriorly, while those of the 1 st 3 abdominal segments point anteriorly.

MYRMICINAE, ATTINI

Trachymyrmex septentrionalis - (Figs. 30-32). Head closely appressed to the body (Figs. 30, 31). Body hairs, which are long, straight, simple (a few with slightly branched apices), are scarce, mostly in ventral region, and weakly papillose (Figs. 30, 31). Ven- 


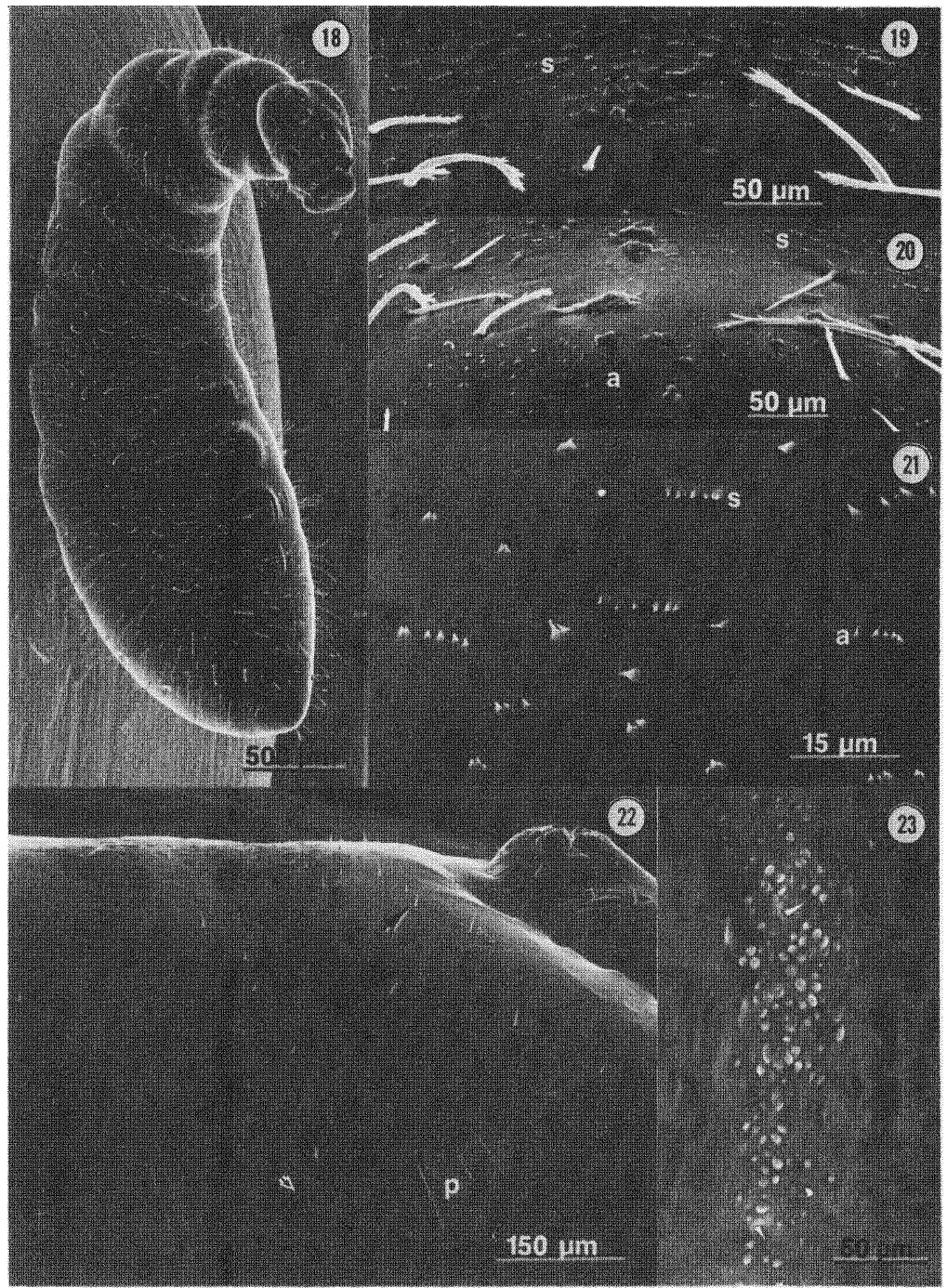

Figs. 18-23. Fig. 18. Lateral view of Pogonomyrmex barbatus. Fig. 19. Ventral region of 2 nd abdominal segment of $P$. barbatus. Note rows of posteriorly pointing, anterior spinules (s). Fig. 20. Ventral region of 3 rd abdominal segment of $P$. barbatus. Note rows of posteriorly pointing, anterior (s) and anteriorly pointing, posterior (a) spinules. Fig. 21. Anteriorly (a) and posteriorly (s) pointing spinules on ventral region of 4th abdominal segment of $P$. barbatus. Fig. 22. Anteroventral region of Crematogaster laeviuscula, showing hairs (large arrow), papillae (small arrow), and pleats (p). Fig. 23. High magnification of papillae of $C$. laeviuscula. 


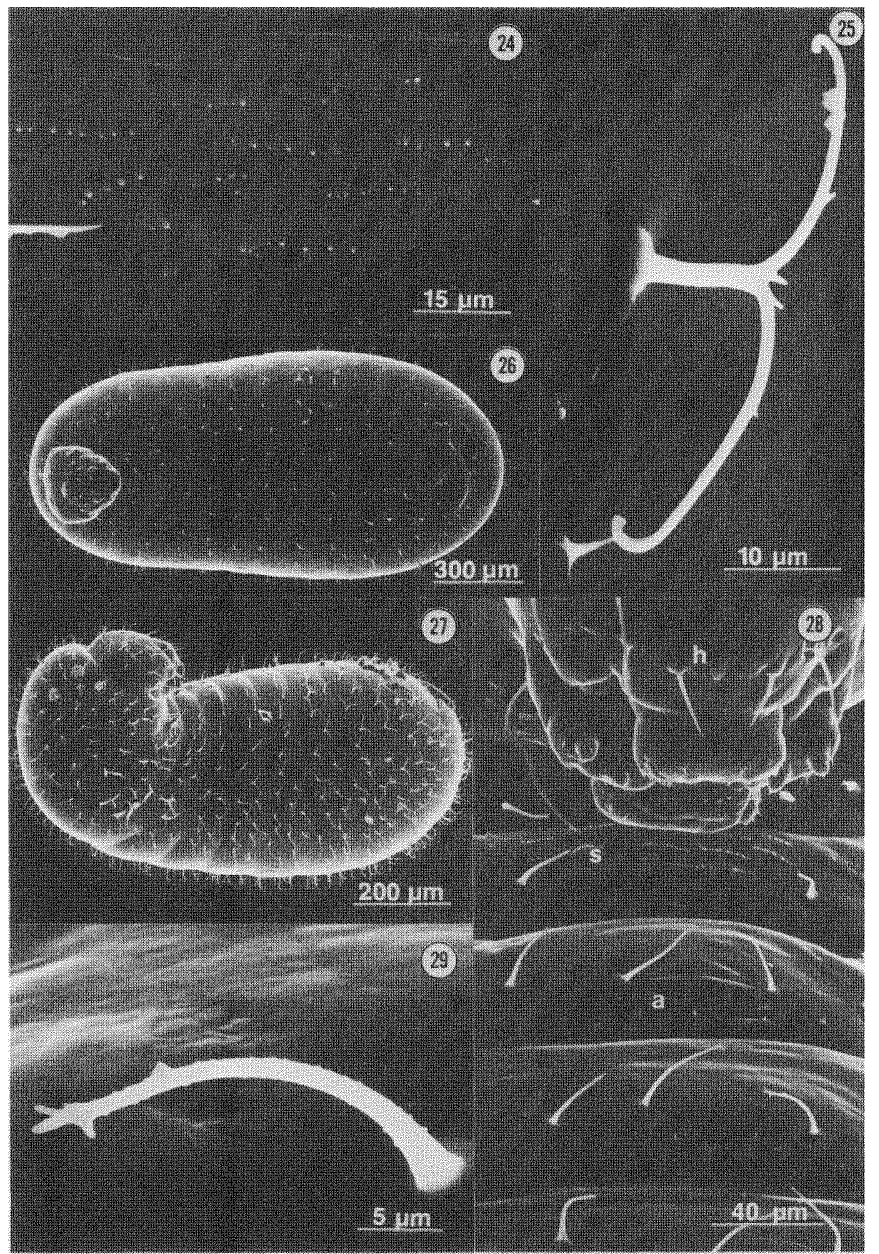

Figs. 24-29. Fig. 24. Posteriorly pointing, ventral spinules of metathorax of Monomorium pharaonis. Fig. 25. Bifid body hairs of M. pharaonis. Fig. 26. Ventral view of $M$. pharaonis. Fig. 27. Ventrolateral view of Solenopsis molesta. Note simple hairs of anteroventral region (arrow). Fig. 28. Anteroventral region of $S$. molesta. Note posteriorly ponting, anterior (s) and anteriorly pointing, posterior (a) spinules. Head (h). Fig. 29. Papillose hair from anteroventral region of $S$. molesta. 
tromedial hairless area relatively wide on thorax, as in S. molesta (Fig. 30). Minute, posteriorly pointing spinules in short rows on ventromedial area of prothorax and mesothorax (Fig. 32).

Atta texana - (Figs. 33-35). Head closely appressed to body (Fig. 33). Leg vestiges prominent (Fig. 33). Body almost hairless. Ventral area of prothorax bears a medial boss bearing numerous spinules pointing straight outward, and 2-6 very short hairs (Figs. 34, 35); other spinules on prothorax point posteriorly (Figs. 34, 35); 2 pairs of very short hairs lateral to boss. Ventromedial area of mesothorax bare of hair and spinules, but flanked laterally by numerous spinules, most pointing straight outward or anteriorly, and 1 pair of very short hairs. Spinules present on succęeding segments.

DOLICHODERINAE, TAPINOMINI

Iridomyrmex pruinosum - (Figs. 36-38). Head appressed closely to body (Figs. 36, 37). Anteroventral region with short, simple hairs, numerous only on prothorax. A very few, minute, blunt spinules are located on the ventral surface of the prothorax and mesothorax; spinules become slightly more numerous on posterior segments (Fig. $38)$.

FORMICINAE, CAMPONOTINI

Colobopsis pylartes - (Figs. 39, 40). Thorax stouter than in Camponotus rasilis. Praesaepium on 1st abdominal segment is covered by welt of 2 nd abdominal segment (Fig. 39). Medial, hairless area of anteroventral region flanked by long, simple hairs (Fig. 39). Spinules very blunt and point posteriorly, those on lateral flanks of praesaepium (1st 2 abdominal segments) point postero-medially; rows of spinules on meso- and metathoracic segments very well developed and prominent (Fig. 40).

Camponotus rasilis - (Figs. 41-43). Neck developed (Fig. 41). Praesaepium well developed, formed in thorax and 1st 2 abdominal segments (Figs. 41, 42). In some specimens, food, including some brown cuticular material was found in praesaepium. Ventral area of prothorax bears numerous long, simple or bifid hairs. Ventromedial, hairless area of meso- and metathorax and 1st 2 abdominal segments is flanked laterally by a few simple bifid hairs. Most other body hairs are 3-5 branched, interspersed occasionally with a few, very long simple hairs with curled tips. Spinules on anteroventral body region (thorax and 1st 2 abdominal segments) point posteriorly (Fig. 43), except for the most anterior portions of the prothorax where they point anteriorly. 


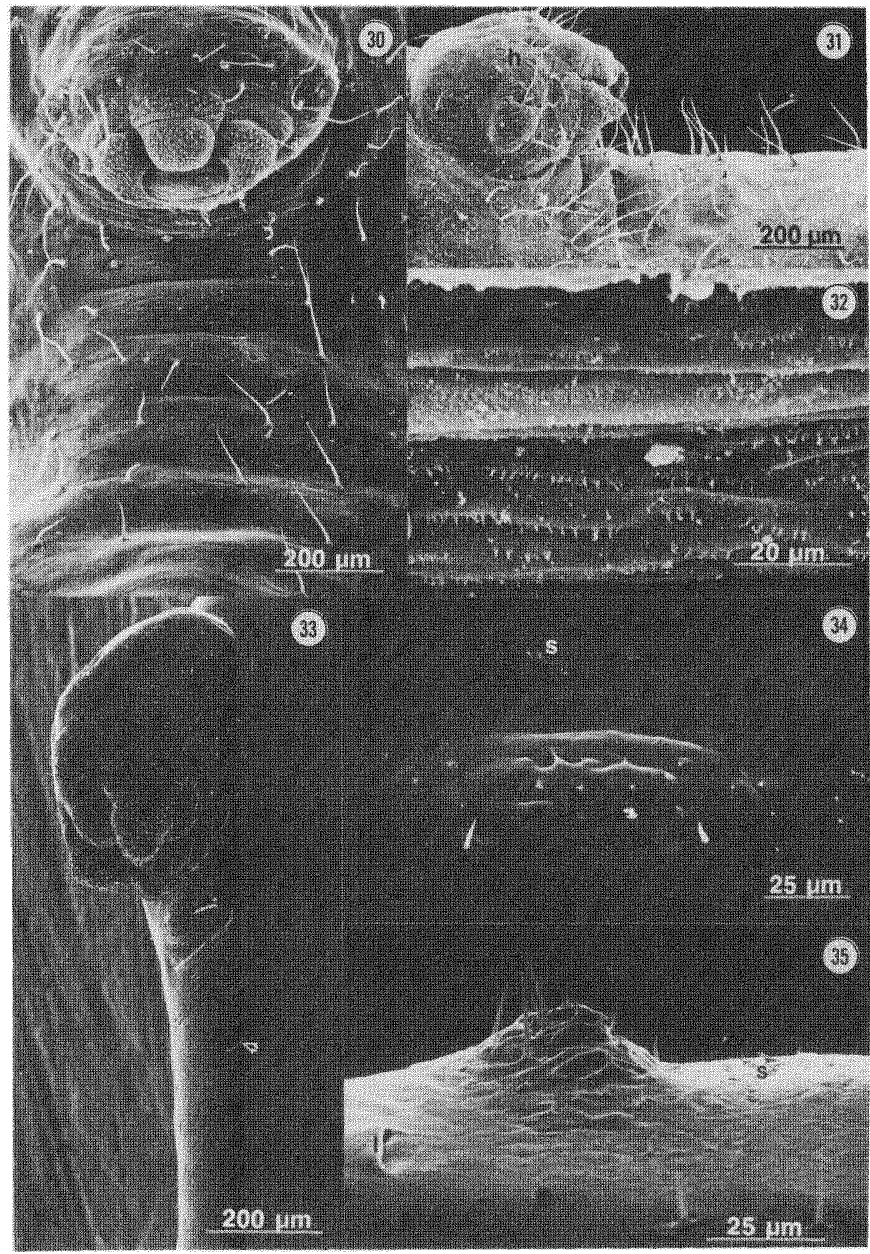

Figs. 30-35. Fig. 30. Ventral view of anteroventral region of Trachymyrmex septentrionalis. Note simple hairs (arrow). Fig. 31. Lateral view of anteroventral region of $T$. septentrionalis. Note simple hairs (arrow). Head (h). Fig. 32. Posteriorly pointing ventral prothoracic spinules of $T$. septentrionalis. Fig. 33. Ventrolateral view of anteroventral region of Atta texana. Note prothoracic boss (large arrow) and metathoracic leg vestige (small arrow). Fig. 34. Ventral view of prothoracic boss of $A$. texana. Note posteriorly pointing spinules (s) anterior to the boss.

Fig. 35. Lateral view of prothoracic boss of $A$. texana. Note posteriorly pointing spinules (s) anterior to the boss, and left prothoracic leg disc (1). 


\section{Discussion}

The morphology of the ventral body region can be related to feeding behavior. Thus, in larvae which are reported in the literature to be fed only by regurgitation of liquid food from the adult workers, the morphology of this region is relatively unspecialized. In this category can be placed Crematogaster laeviuscula and Iridomyrmex pruinosum, in which the head is so closely appressed to the body, that it cannot reach the ventral body region with its mouthparts. Larvae of these species bear few or no spinules in this region and the hairs and hair pattern are unspecialized. The papillose regions on $C$. laeviuscula may be vestiges of the rows of spinules found in other ants. Wheeler and Wheeler (1976) state: "... the immobility of a body with a dolichoderoid or crematogastroid shape precludes self-feeding. Hence these larvae must be fed by regurgitation".

The remaining larvae described in this study are reported in the literature to be fed solid food by adult workers.

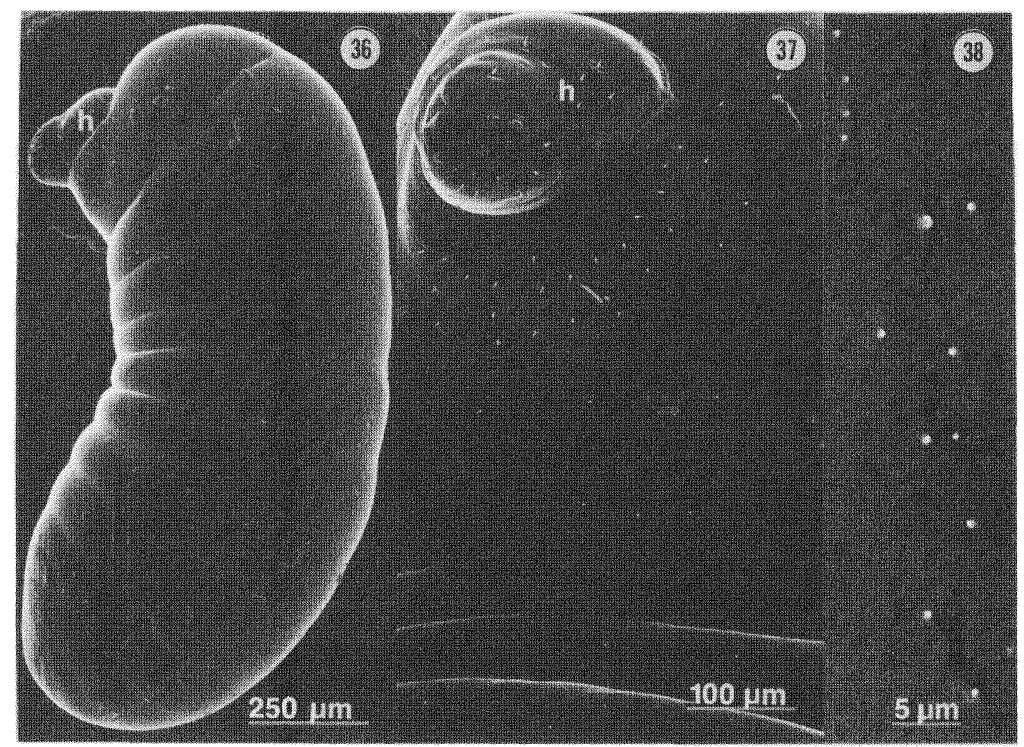

Figs. 36-38. Fig. 36. Lateral view of Iridomyrmex pruinosum. Head (h). Fig. 37. Anteroventral body region of I. pruinosum. Note short, simple hairs (arrow). Praesaepium (arrow). Fig. 38. Ventral, metathoracic spinules of I. pruinosum. 


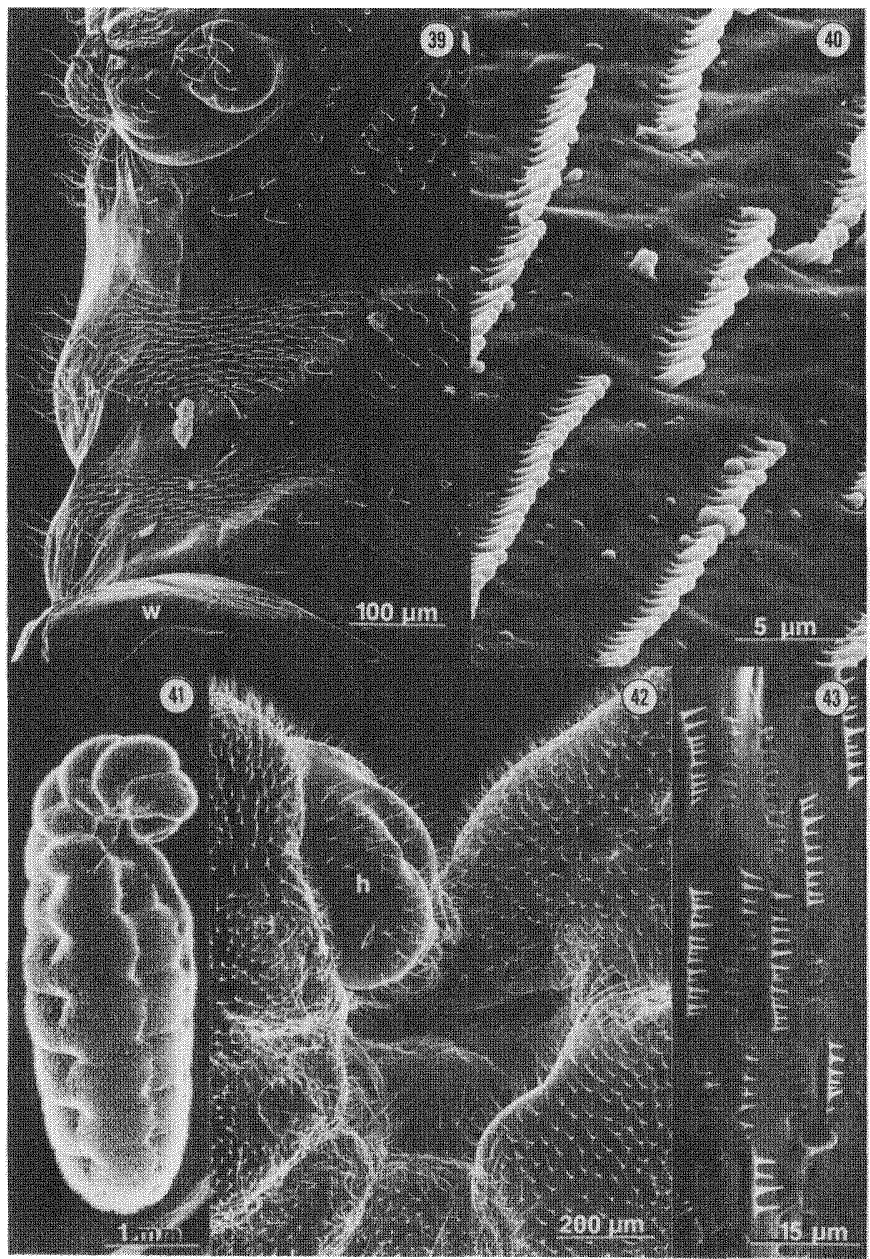

Figs. 39-43. Fig. 39. Anteroventral region of Colobopsis pylartes. Note rows of spinules (arrows) and welt (w). Fig. 40. Posteriorly pointing ventral thoracic spinules of $C$. pylartes magnified from Fig. 39. Fig. 41. Ventrolateral view of Camponotus rasilis. Praesaepium (arrow). Fig. 42. High magnification of praesaepium of $C$. rasilis. Head (h). Fig. 43. Posteriorly pointing ventral thoracic spinules of $C$. rasilis. 
However, larvae of Neivamyrmex nigrescens (Dorylinae) do not show specializations for holding food. In studies based on the laboratory culture methods of Topoff and Mirenda (1978a, b), workers placed prey near larvae, which then attached themselves to this food and appeared to suck out the body fluids (Mirenda, pers. comm.). Thus, larvae of $N$. nigrescens do not require a specialized ventral feeding region as food is never placed on them. Wheeler and Bailey $(1920: 270)$ do not describe how ant larvae in the Dorylinae are fed "pellets made of the flesh of insects".

The simplest arrangement of morphology for holding solid food is found in some Myrmicinae. The 2 species from Solenopsidini described above (Monomorium pharaonis, Solenopsis molesta) bear similar general patterns of vestiture on the anteroventral region, i.e. with anterior spinules pointing posteriorly and posterior spinules pointing anteriorly, and with hairs mostly simple. Furthermore, the position of the head and curvature of the thorax give them the ability to reach the anteroventral region. Similar morphology was described for S. invicta (Petralia and Vinson 1978, 1979). The anteroventral region is least specialized in $M$. pharaonis and it is not known whether this region is used for holding food. Larvae of S. invicta and $S$. molesta feed on solid food placed on them (Petralia and Vinson 1978, Wheeler and Wheeler 1955), and in S. invicta the hairs and spinules of the anteroventral region are efficient for holding solid food while the larva feeds upon it (Petralia and Vinson 1978). The hairs surrounding the hairless medial area enclose the food particle to form a "food basket", while the medial spinules are arranged to assist attachment of the food. S. molesta appears to have a somewhat similar "food basket".

A comparable means of holding food is found on larvae in the Attini. Trachymyrmex septentrionalis bears well developed hairs only on the ventral region, with the majority being in the anteroventral region. These hairs appear to be aranged in a similar pattern as in Solenopsis. Thus, this may also be a "food basket" since Wheeler and Wheeler $(1974,1976)$ state: "The ventral hairs of the attine larvae keep the fungal mass [food] firmly in place while the larva is feeding". Atta texana is almost bare of hairs but possesses a ventral prothoracic boss with outward pointing spinules and minute hairs. G. C. Wheeler (1948) describes how adult workers place solid food on the mouthparts of these larvae. We speculate that larvae may use this structure 
to brace or anchor the food while feeding, because of the close proximity of this boss to the face of the mouthparts, although this is not described in the literature.

The most efficient method for holding solid food, within the Myrmicinae, may be in larvae of Pogonomyrmex barbatus. The segments in the posteroventral feeding region (especially abdominal segments 3-5) bear spinules and strongly denticulate hairs, both pointing to the center of each segment. The attenuated thorax allows larvae enough dexterity to feed easily from this region.

This attenuation is even more pronounced in the Ponerinae. The larvae of Ponerinae described here have a long neck which allows them to reach solid food placed on the wide, flattened posteroventral body region which Wheeler and Wheeler (1976) refer to as a food "platter." W. M. Wheeler (1918) describes the feeding behavior of Odontomachus: "These larvae are placed by the ants on their broad backs, and their heads and necks are folded over onto the concave ventral surface, which serves as a table or trough on which food is placed by the workers." This "food platter" is visible in O. clarus and Pachycondyla villosa where a row of tubercles demarcates this area laterally. It is better developed in $P$. villosa in which a circle of spinules on each segment probably holds food more efficiently than the posteriorly pointing spinules in $O$. clarus. The arrangement of spinules in $P$. villosa may be comparable to that on the posteroventral feeding region of $P$. barbatus (Myrmicinae).

The feeding region on larvae of the ponerine Leptogenys elongata may be even more specialized by the development of a unique cuticular process on the ventral surface of the 3rd abdominal segment. The cuticular ridges in this structure seem to be formed from a fusion of the small, blunt papillae or spinules, as is visible in the peripheral parts of the structure. Thus, these ridges are probably homologous to the rows of spinules common on ant larvae. We speculate that this structure may form a "food tray," efficient in holding solid food while the larva feeds upon it. ${ }^{3}$ Recently, John Mirenda and the authors have made preliminary observations on larval feeding in live colonies of L. elongata. ${ }^{4}$ Adult workers place larvae head first into the par-

\footnotetext{
${ }^{3}$ Dr. G. C. Wheeler and J. Wheeler suggest that this structure might function as a stridulatory or food-holding structure or both (pers. comm.).

${ }^{4}$ Collected and identified by Dr. J. Mirenda, from College Station (Brazos Co.), TX (March 3, 1980).
} 
tially eaten bodies of isopods, where larvae actively feed. Since Wheeler (1918) states that the larvae of North American Ponerinae feed on food placed on their ventral region, or on insect parts placed near them (observed in L. elongata; 1910), it is possible that several methods of feeding are present in the same species. However, an alternative function of the ridged structure is a holdfast. When not feeding, larvae typically curve their "necks" so as to rest the ventral surface of the prothorax or the posteroventral surface of the head against the ridged structure. Perhaps posteriorly pointing spinules hook on the ridges, allowing the larva to maintain the resting position with minimum effort.

The most advanced specializations for holding food are found in the Pseudomyrmecinae and the Camponotini. Many larvae of the Camponotini possess a well developed pocket for holding solid food called a praesaepium (Wheeler and Wheeler 1953). It is best developed in Colobopsis as is evident in C. pylartes. In both Camponotus rasilis and $C$. pylartes the posteriorly pointing spinules on the anteroventral region may function to force the food against the posterior wall of the praesaepium (the posterior wall in Colobopsis is the large ventral welt). This is supported by illustrations of a food pellet held in the praesaepium of $C$. gasseri (Forel) (Wheeler and Wheeler 1970).

The "food pocket" is most highly developed in the Pseudomyrmecinae and is called the trophothylax (Wheeler and Bailey 1920; Wheeler and Wheeler 1956). The spinules in the trophothylax are positioned to help hold food in it, although this assistance may be unnecessary.

Specialized feeding regions are also described in larvae of other social Hymenoptera, including the transitory praesaepium of allodapoid bees and some vespids, and the shelf of Mischocyttarus (Vespidae: Polybiinae) (Wheeler and Wheeler 1979). We thus assume that morphological adaptations for holding food on the ventral region have evolved independently in numerous taxa within the social Hymenoptera.

In conclusion, the various morphological specializations in the feeding regions of ant larvae are analogous, although not always homologous. Thus, 3 basic types of feeding regions are evident. The first is the "food basket" of larvae of some Myrmicinae, in which the specializations are in the arrangement of homologous groups of 
hairs and spinules. The second is the posteroventral "food platter" of larvae of most Ponerinae, in which specializations are in the arrangement of homologous groups of spinules and tubercles. The 3rd is the anteroventral "food pocket" of larvae of Pseudomyrmecinae and Camponotini, in which specializations are in the arrangement of homologous groups of spinules and in the homologous development of the pockets.

\section{ACKNOWLEDGMENTS}

Appreciation is extended to Dr. John T. Mirenda for identifying some of the species, Dr. H. R. Burke for his advice and suggestions, and Dr. G. C. Wheeler and J. Wheeler for their critical review. We also thank David Ball, Dr. Margaret R. Barlin, Daniel Bogar, William P. Foerster, Dr. John T. Mirenda, and Dr. John Moser for providing specimens of $P$. barbatus, $C$. rasilis, $M$. pharaonis, $C$. laeviuscula, $N$. nigrescens, and $A$. texana, respectively.

Petralia, R. S. and S. B. Vinson

\section{References Cited}

1978. Feeding in the larvae of the imported fire ant, Solenopsis invicta: behavior and morphological adaptations. Ann. Entomol. Soc. Amer. 71: 643-8.

1979. Developmental morphology of larvae and eggs of the imported fire ant, Solenopsis invicta Buren. Ann. Entomol. Soc. Am. 72: 472-84.

Topoff, H. AND J. Mirenda.

1978a. Precocial behavior of callow workers of the army ant Neivamyrmex nigrescens: importance of stimulation by adults during mass recruitment. Animal Behavior 26(3): 689-706.

1978b. In search of the precocial ant. In The Development of Behavior: Comparative and Evolutionary Aspects (M. Bekoff and G. Burghardt, Eds.). New York: Garland.

WHEELER, G. C.

1948. The larvae of the fungus-growing ants. Amer. Midland Natur. 40: 664-89.

Wheeler, G. C. AND J. WhEeler

1953. The ant larvae of the subfamily Formicinae, part II. Ann. Entomol. Soc. Amer. 46: 175-217.

1955. The ant larvae of the myrmicine tribe Solenopsidini. Amer. Midland Natur. 54:119-41.

1956. The ant larvae of the subfamily Pseudomyrmecinae (Hymenoptera: Formicidae). Ann. Entomol. Soc. Amer. 49: 374-98. 
1970. Ant larvae of the subfamily Formicinae: second supplement. Ann. Entomol. Soc. Amer. 63:648-56.

1974. Ant larvae of the myrmicine tribe Attini: second supplement (Hymenoptera: Formicidae). Proc. Entomol. Soc. Wash. 76:78-81.

1976. Ant Larvae: Review and Synthesis. Mem. Entomol. Soc. Wash. 7: 1-108.

1979. Larvae of the social Hymenoptera. In Social Insects, Vol. I. (H. R. Hermann, Ed.). New York: Academic Press.

WHEELER, W. M.

1910. Ants. Columbia Univ. Press, New York, 663 pp.

1918. A study on some ant larvae, with a consideration of the origin and meaning of the social habit among insects. Proc. Amer. Phil. Soc. (Philadelphia) 57: 293-343.

WheEler, W. M. AND I. W. Bailey.

1920. The feeding habits of pseudomyrmine and other ants. Trans. Amer. Phil. Soc. (Philadelphia) (Art. 4): 235-279, 5 pl. 

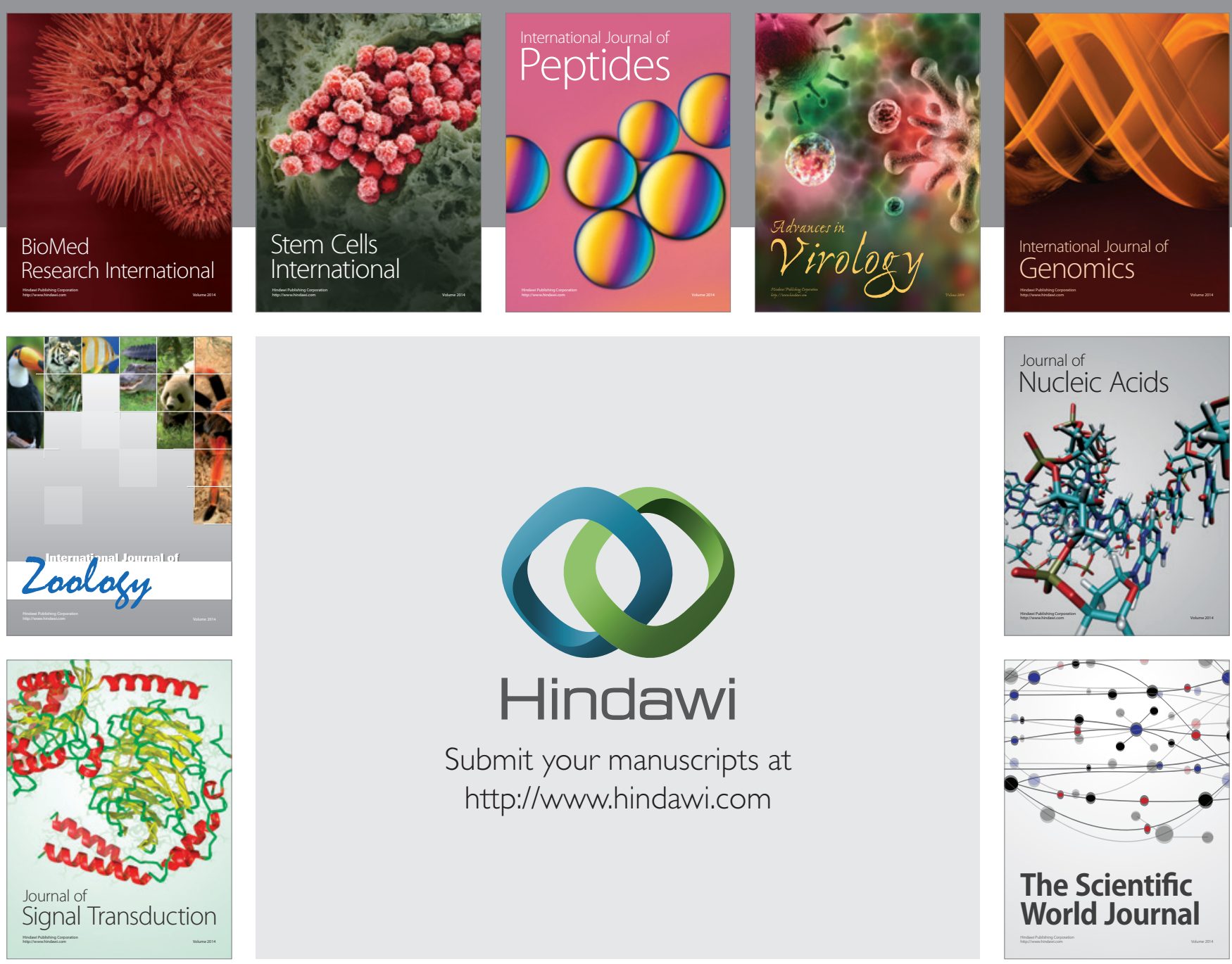

Submit your manuscripts at

http://www.hindawi.com
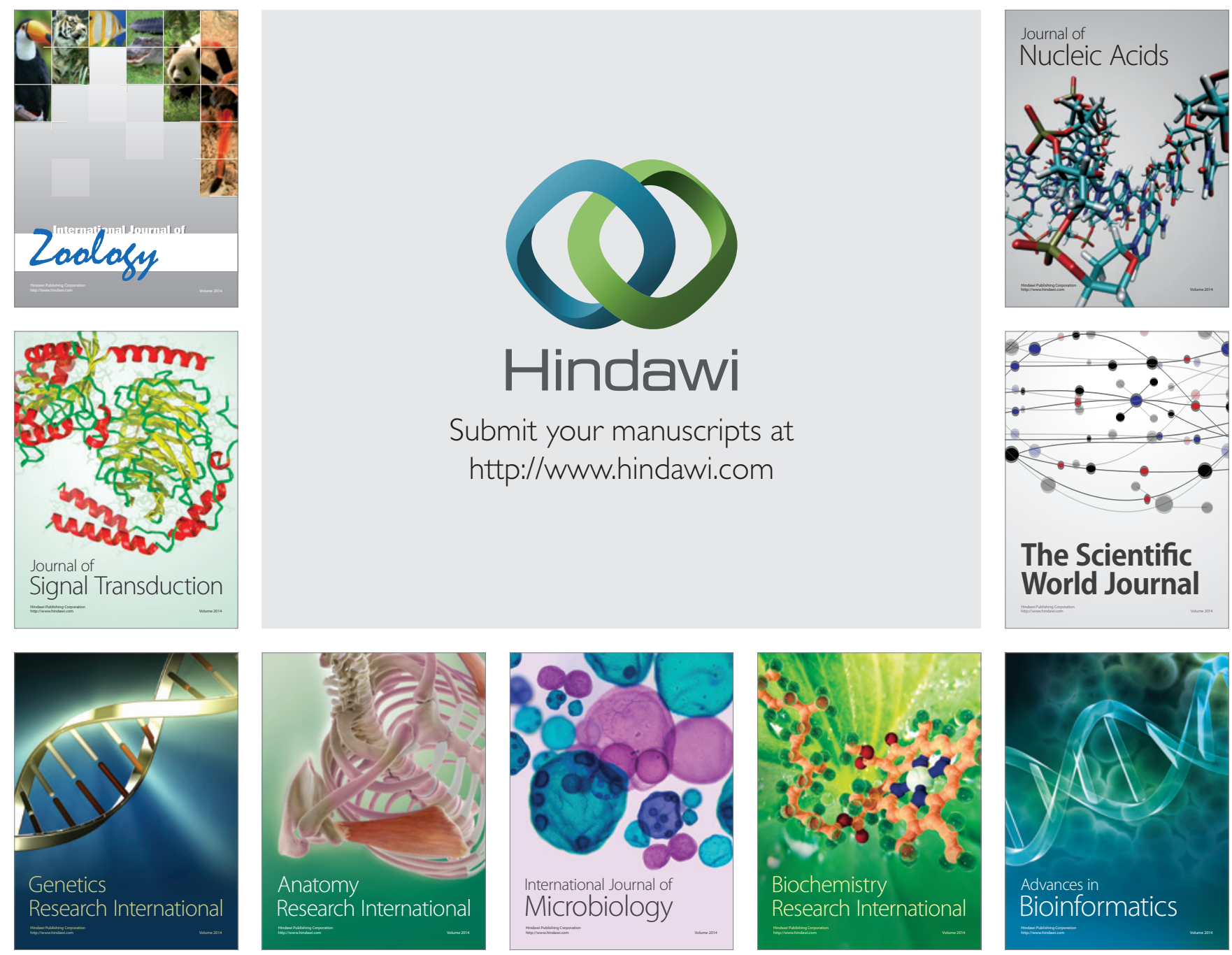

The Scientific World Journal
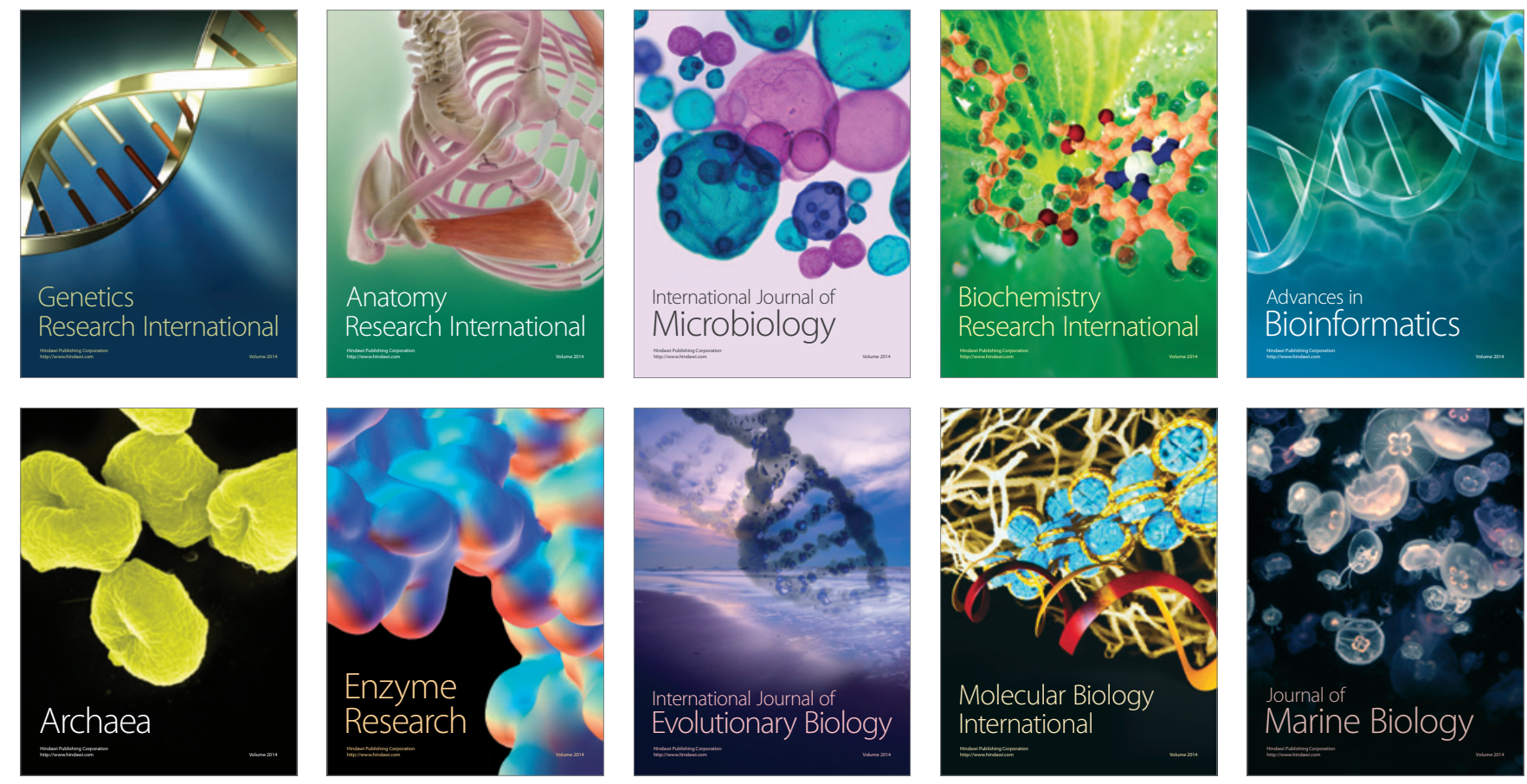